\title{
Molecular detection of lung cancer stem cells
}

\section{Editorial}

According to the International Association for the Study of Lung Cancer (IASLC), the American Thoracic Society (ATS) and the European Respiratory Society (ERS), lung cancers are divided into two groups: SCLC: (Small cell lung cancer) and NSCLC: Non-Small Cell Lung Cancer. ${ }^{1,2}$ Around $15 \%$ of the lung tumors are SCLC and appear in the bronchi, whereas the NSCLS are divided into three histological types: adenocarcinomas, squamous cell carcinoma, and large cell carcinomas. Adenocarcinomas account for about $40 \%$ of the lung cancers and usually occur in the peripheral lung tissue, ${ }^{3}$ squamous carcinomas represent $25 \%$ and are generally located in the central bronchus and the large cell carcinomas (around 20\% of lung cancers) appear to be derived from neuroendocrine cells and can be observed in combination with other types of NSCLC. ${ }^{4}$

Different types of genetic modification have been described in pulmonary tumors such as chromosomal abnormalities, ${ }^{5}$ telomerase activation, ${ }^{6}$ and mutations in oncogenes or tumor suppressor genes such as P53 (Tumor Protein p53),(RB1 Retino Blastoma 1), CDKN2A (Cyclin-Dependent Kinase Inhibitor 2A), KRAS and EGFR (Epidermal Growth Factor Receptor). ${ }^{4}$ Some of these genes can be used as markers of the disease progression, others may have a direct role in the genesis of lung cancers. ${ }^{7}$

Cancer stem cells in the lungs may emerge from progenitor cells or differentiated cells that have acquired self-renewal capacity such as neuroendocrine cells. ${ }^{8}$ Clara variant cells and neuroendocrine cells have been proposed as the cells responsible for bronchopulmonary cancers. ${ }^{9}$ These phenomena are supported by the assumptions of stem cell plasticity, which is defined as the ability to cross the barrier of differentiated cell lines and to adopt phenotypes of other cell types, ${ }^{10}$ as well as the hypothesis of Trans-differentiation. ${ }^{11}$ The phenotypic heterogeneity observed between the different types of lung tumors suggests that the histological environment of the tumor profoundly affects the fate of cancer cells. ${ }^{12}$ And the cell development program of a specific lineage can be altered by changing the signals in the local environment. ${ }^{13}$

The identification of cancer stem cells is based on their phenotype or on the functional characteristics. The SP (Side Population) for example, with its epithelial restorative capacity, has been shown to be resistant to chemotherapy in pulmonary cancers ${ }^{14,15}$ and the over expression of its telomerase suggests that pulmonary SP may represent a source of cancer stem cells with unlimited proliferative potential. ${ }^{14,15}$ Cancer stem cells can also be identified using the cell surface marker CD133 or prominin- $1 .{ }^{16} \mathrm{CD} 133$ is expressed in hematopoietic, endothelial, neural and in many tumors such as brain and pulmonary tumors. ${ }^{17}$ But the lack of specific markers of pulmonary progenitors represents a major problem in the isolation of pulmonary cancer stem cells. The markers known as CD133, ABCG2 (ATP Binding Cassette sub-family $\mathrm{G}$ member 2 ) and IL-6R (Interleukin 6 Receptor) ${ }^{18}$ are not always effective in sorting for the population of cancer stem cells. ${ }^{19}$

Another method for the identification of tumor-derived pulmonary stem cells is the detection of the increased activity of ALDH (Aldehyde dehydrogenase). This enzyme is responsible for the
Volume 2 Issue 2 - 2017

\author{
Alain Abi-Rizk, Walid H leihel \\ Holy Spirit University of Kaslik (USEK), Faculty of Agricultural \\ and Food Sciences, Lebanon \\ Correspondence: Alain Abi-Rizk, Holy Spirit University \\ of Kaslik (USEK), Faculty of Agricultural and Food Sciences, \\ Lebanon,Email alainabirizk@usek.edu.lb
}

Received: March 02, 2017 | Published: March 14, 2017

intracellular oxidation of aldehydes and is over expressed in stem cells and cancer stem cells. ${ }^{17,20}$ Furthermore, transcriptional deregulation can activate oncogenes and / or deactivate tumor suppressor genes. ${ }^{21}$ RUNX (Runt-related transcription factors) genes, for example, have oncogenic and tumor suppressor characteristics. These genes encode transcription factors involved in normal tissue development. Many chromosomal translocations involving RUNX genes lead to the formation of oncogenic fusion proteins. ${ }^{22}$ RUNX3 is an essential transcription factor in the late phase of pulmonary development. It is necessary for the control of the differentiation and proliferation of the bronchiolar epithelium..$^{23}$ Its sub-regulation by hyper-methylation has been observed in pulmonary adenocarcinomas ${ }^{24,25}$ and has even been proposed as an early event in the development of pulmonary carcinomas by inhibiting the differentiation of progenitor cells. ${ }^{23}$

TTF1 (Thyroid transcription factor-1) may be a specific Oncogene of pulmonary adenocarcinomas ${ }^{26}$ and BRF2 (B-Related Factor 2) a specific Oncogene of squamous cancers. ${ }^{27}$ OCT4 (Octamer Binding Factor 4) is a transcriptional factor of embryonic stem cells that may induces apoptosis of cancer stem cells. ${ }^{28}$ SOX2 (SRY (sex determining region Y)-box 2) controls the self-renewal and differentiation of stem cells and is involved in correct branching and lung morphogenesis. ${ }^{29,30}$ SOX2 has been proposed as an Oncogene whose expression is essential in pulmonary tumor stem cells to induce carcinogenesis. ${ }^{31,32}$

In human, c-kit (Cell receptor tyrosine kinase) proved to be a promoter of tumor growth. ${ }^{33,34}$ Patients with an over-expression of c-Kit in cancer stem cells have lower survival rates than those who do not and show evidence of resistance to chemotherapy ${ }^{35}$ The blockade of the c-Kit pathway inhibits the proliferation and survival of tumor stem cells after chemotherapy. ${ }^{36}$ The knowledge of the signaling pathways of pulmonary cancer stem cells could lead to the development of new therapies capable of eliminating these cells. The methods developed for the detection of cancer stem cells described above and the coherence of the preclinical data on the transcription factors such as RUNX3, OCT4, SOX2, and c-Kit represent a major scientific development for the survival and healing of patients.

\section{Acknowledgements}

None.

\section{Conflict of interest}

Author declares that there is no conflict of interest. 


\section{References}

1. Field JK, Smith RA, Aberle DR, et al. International association for the study of lung cancer computed tomography screening workshop 2011 report. Journal of Thoracic Oncology. 2012;7(1):10-19.

2. Travis WD, Brambilla E, Noguchi M, et al. International association for the study of lung cancer/american thoracic society/european respiratory society international multidisciplinary classification of lung adenocarcinoma. Journal of thoracic oncology. 2011;6(2):244-285.

3. Collins LG, Haines C, Perkel R, et al. Lung cancer: diagnosis and management. Am Fam Physician. 2007;75(1):56-63.

4. Rivera C, Rivera S, Loriot Y, et al. Lung cancer stem cell: new insights on experimental models and preclinical data. Journal of oncology. 2010

5. Yanada M, Yaoi T, Shimada J, et al. Frequent hemizygous deletion at $1 \mathrm{p} 36$ and Hypomethylation down regulate RUNX3 expression in human lung cancer cell lines. Oncology reports. 2005;14(4):817-822.

6. Hiyama K, Hiyama E, Ishioka S, et al. Telomerase activity in small-cell and non-small-cell lung cancers. J Natl Cancer Inst. 1995;87(12):895-902.

7. Amos CI, Xu W, Spitz MR. Is there a genetic basis for lung cancer susceptibility? Recent Results Cancer Res. 1999;151:3-12.

8. Visvader JE, Lindeman GJ. Cancer stem cells in solid tumours: accumulating evidence and unresolved questions. Nat Rev Cancer. 2008;8(10):755-768.

9. Reynolds SD, Giangreco A, Power JH, et al. Neuroepithelial bodies of pulmonary airways serve as a reservoir of progenitor cells capable of epithelial regeneration. Am J Pathol. 2000;156(1):269-278.

10. Eisenberg LM, Eisenberg CA. Stem cell plasticity, cell fusion, and transdifferentiation. Birth Defects Res C Embryo Today: Reviews. 2003;69(3):209-218.

11. Forbes SJ, Pamela VIG, Poulsom R, et al. Adult stem cell plasticity: new pathways of tissue regeneration become visible. Clin Sci. 2002;103(4):355-369.

12. Meuwissen R, Berns A. Mouse models for human lung cancer. Genes \& development. 2005;19(6):643-664.

13. Ohtsuka N, Urase K, Momoi T, et al. Induction of bud formation of embryonic mouse tracheal epithelium by fibroblast growth factor plus transferrin in mesenchyme $\square$ free culture. Dev Dyn. 2001;222(2):263-272.

14. Ho MM, $\mathrm{Ng} \mathrm{AV}$, Lam $\mathrm{S}$, et al. Side population in human lung cancer cell lines and tumors is enriched with stem-like cancer cells. Cancer res. 2007;67(10):4827-4833.

15. Salcido CD, Larochelle A, Taylor BJ, et al. Molecular characterization of side population cells with cancer stem cell-like characteristics in smallcell lung cancer. Br J Cancer. 2010;102(11):1636-1644.

16. Summer R, Kotton DN, Sun X, et al. Side population cells and Bcrp1 expression in lung. Am J Physiol Lung Cell Mol Physiol. 2003;285(1):L97-L104.

17. Miyata T, Yoshimatsu T, Sekimura A, et al. Cancer stem cell markers (ALDH1 and CD133) expression could be associated with a poor prognosis in the patients with lung adenocarcinoma. Cancer Research. 2016;76(14):16-20.

18. Yi H, Cho HJ, Cho SM, et al. Effect of 5-FU and MTX on the expression of drug-resistance related cancer stem cell markers in non-small cell lung cancer cells. Korean J Physiol Pharmacol. 2012;16(1):11-16.
19. Eramo A, Haas TL, De Maria R. Lung cancer stem cells: tools and targets to fight lung cancer. Oncogene. 2010;29(33):4625-4635.

20. Ginestier C, Hur MH, Charafe-Jauffret E, et al. ALDH1 is a marker of normal and malignant human mammary stem cells and a predictor of poor clinical outcome. Cell stem cell. 2007;1(5):555-567.

21. Bishop JM. The molecular genetics of cancer. Science. 1987;235(4786):305-311.

22. Cameron ER, Neil JC. The Runx genes: lineage-specific oncogenes and tumor suppressors. Oncogene. 2004;23(24):4308-4314.

23. Lee KS, Lee YS, Lee JM, et al. Runx3 is required for the differentiation of lung epithelial cells and suppression of lung cancer. Oncogene. 2010;29(23):3349-3361.

24. Li QL, Kim HR, Kim WJ, et al. Transcriptional silencing of the RUNX3 gene by $\mathrm{Cp}$ Ghypermethylation is associated with lung cancer. Biochem Biophys Res Commun. 2004;314(1):223-228.

25. Licchesi JD, Westra WH, Hooker CM, et al. Epigenetic alteration of Wnt pathway antagonists in progressive glandular neoplasia of the lung. Carcinogenesis. 2008;29(5):895-904.

26. Kwei KA, Kim YH, Girard L, et al. Genomic profiling identifies TITF1 as a lineage-specific oncogene amplified in lung cancer. Oncogene. 2008;27(25):3635-3640.

27. Lockwood WW, Chari R, Coe BP, et al. Integrative genomic analyses identify BRF2 as a novel lineage-specific oncogene in lung squamous cell carcinoma. PLoS Med. 2010;7(7):e1000315.

28. Hu T, Liu S, Breiter DR, et al. Octamer 4 small interfering RNA results in cancer stem cell-like cell apoptosis. Klinische Pädiatrie. 2012;224(7):A9

29. Gontan C, de Munck A, Vermeij M, et al. Sox 2 is important for two crucial processes in lung development: branching morphogenesis and epithelial cell differentiation. Developmental biology. 2008;317(1):296-309.

30. Ishii Y, Rex M, Scotting PJ, et al. Region-specific expression of chicken Sox2 in the developing gut and lung epithelium: regulation by epithelial-mesenchymal interactions. Developmental dynamics. 1998;213(4):464-475.

31. Hussenet T, Dali S, Exinger J, et al. SOX2 is an oncogene activated by recurrent $3 \mathrm{q} 26$. 3 amplifications in human lung squamous cell carcinomas. PloS one. 2010;5(1):e8960.

32. Takahashi K, Yamanaka S. Induction of pluripotent stem cells from mouse embryonic and adult fibroblast cultures by defined factors. Cell. 2006;126(4):663-676.

33. Hines SJ, Organ C, Kornstein MJ, et al. Coexpression of the c-kit and stem cell factor genes in breast carcinomas. Cell growth differ. 1995;6(6):769-779.

34. Krystal GW, Hines SJ, Organ CP. Autocrine growth of small cell lung cancer mediated by Coexpression of c-kit and stem cell factor. Cancer research. 1996;56(2):370-376.

35. Hassan HT. c-Kit expression in human normal and malignant stem cells prognostic and therapeutic implications. 2009.

36. Levina V, Marrangoni A, Wang T, et al. Elimination of human lung cancer stem cells through targeting of the stem cell factor-c-kit autocrine signaling loop. Cancer res. 2010;70(1):338-346. 